\title{
Police patrols for alcohol-related crashes: more rigorous evaluation needed
}

Driving vehicles after drinking alcohol is common, and has been shown to increase the risk of car crashes. ${ }^{1}$ There is a strong community perception that increased police patrols are effective in reducing dangerous driving practices such as drinkdriving. A recently published review on the Cochrane Database of Systematic Reviews has examined the effectiveness of police patrols for reducing crashes and crash-related injuries. $^{2}$

Police patrols were the main intervention examined in the review, and were defined as an increase in the number of officers or in the frequency and duration of patrols, with the intention of identifying impaired drivers via behavioral cues. Most included studies (91\%) assessed increased patrols in combination with other programs such as media campaigns or special training for police officers. Therefore, it was generally not possible to evaluate the independent effect of each element of the intervention.

As the interventions were implemented in the community, studies designed to evaluate effectiveness at a community level were included in the review. Study designs included randomized trials, interrupted time series, and controlled before-and-after studies. The authors found many methodological problems with the included studies, including lack of detail, which made quality assessment difficult. Of the 32 eligible studies, two-thirds scored "not adequate" on at least one feature for assessing methodological quality.

Although the studies included in the review were generally consistent in showing positive effects on traffic crashes and deaths, these effects were not always statistically significant at the $95 \%$ confidence level, particularly for studies examining fatal crashes. However, 13 of 20 studies showed reductions in total crashes, and two-thirds of these reductions were statistically significant. The review authors concluded that, although the effects were reasonably consistent across studies, methodological weaknesses (including inadequate sample size, failure to match on baseline measures, contamination, and inadequate data analysis) precluded making firm conclusions about the effectiveness of increased police patrols, whether or not the patrols were in combination with other interventions.

The review authors commented on the need for high-quality evaluations of interventions. Substantial resources are spent on crash-reduction programs despite their unproven efficacy. Therefore, government agencies should be encouraged and supported in the design, conduct, and publication of rigorous evaluations for implemented programs.

\section{R Ivers}

R Ivers
Health Sydney, Australia

The Cochrane Injuries Group invited Amy Aeron-Thomas, Executive Director of the UK crash victim's charity RoadPeace and author of a related Cochrane review, ${ }^{3}$ to comment on the findings of this new review. Her comments are below.

Drink-driving is a crime that results in the death of over 10000 people in the EU each year. ${ }^{4}$ In the UK, 460 people died in drink-drive-related crashes in 2007, 18\% fewer than in $2006 .^{5}$ One in six UK road deaths is drink-driverelated. ${ }^{6}$ The problem of drink-driving is more prevalent at night, with half of all night-time driver fatalities being over the drink-drive limit. ${ }^{6}$

The UK is one of the last countries in the EU to have a drink-drive limit of 80 $\mathrm{mg}$ of alcohol per $100 \mathrm{ml}$ of blood, ${ }^{7}$ but this limit will soon be re-evaluated by the Department for Transport (DfT). The DfT has previously argued against reducing the limit to $50 \mathrm{mg} / 100 \mathrm{ml}$ on the basis that it was more important to first properly enforce the existing limit. ${ }^{8}$ Increased breath tests and police patrols are standard recommendations. The Goss et $a l^{2}$ review is timely, as the DfT is about to launch a consultation on reducing drink-driving, and the effectiveness of police patrols will be re-examined.

More traffic police officers spending more time on patrol instead of on paperwork are common calls by the public and tabloid newspapers. Traffic police numbers have decreased over the past 10 years ${ }^{9}$ with the increased concern over terrorism and street crime. Increased reporting requirements for police officers has also contributed to a decline in their presence on the road. Speed cameras are considered to be less useful than police patrols, as cameras are not able to catch dangerous or drunk drivers. Increased police patrols are perceived to be effective at detecting and deterring sober and impaired bad driving in general.

It is disappointing that the Goss et $a l^{2}$ review was not able to make any firm conclusions because of the lack of quality of the studies. Drink-drive campaigns have been conducted over decades, and a variety of study data exist. Sponsorship of drink-driving campaigns, including increased enforcement, is a common activity by insurance companies, which are keen to monitor risk levels and costeffectiveness.

The lack of good-quality studies is not unique to this review. Many countries are preparing a road safety strategy to take them through the next decade. A common recommendation should be for all road safety programs to be evaluated with a research design, approved in advance of the start of the program, which is comparable to other studies already in existence.

In the UK, the DfT's new chief medical advisor is, for the first time ever, from the public health sector, and it is hoped that he will be able to promote policy based on hard evidence rather than popular support. Drink-driving needs more than good intentions to prevent it. More goodquality evidence on the best way to prevent drink-driving is necessary.

For more information on the Cochrane Collaboration please visit www.cochrane. org or www.injuries.cochrane.org or email Emma Sydenham, Review Group Coordinator of the Cochrane Injuries Group at Emma.Sydenham@1shtm.ac.uk. The Cochrane Collaboration offers training at centers worldwide for potential review authors - see the website for details.

\section{A Aeron-Thomas RoadPeace, London, UK}

Correspondence to: Dr R 0 Ivers, The George Institute for International Health, Sydney, Australia; rivers@ george.org.au

\section{Competing interests: None.}

Injury Prevention 2008;14:408-409

doi:10.1136/ip.2008.020552

\section{REFERENCES}

1. Chou SP, Dawson DA, Stinson FS, et al. The prevalence of drinking and driving in the United States, 2001-2002: results from the national epidemiological survey on alcohol and related conditions. Drug Alcohol Depend 2006;83:137-46. 
2. Goss CW, Van Bramer LD, Gliner JA, et al. Increased police patrols for preventing alcohol-impaired driving. Cochrane Database Syst Rev 2008;(4):CD005242.

3. Aeron-Thomas AS, Hess S. Red-light cameras for the prevention of road traffic crashes. Cochrane Database Syst Rev 2005;(2):CD003862.

4. European Transport Safety Council. ETSC fact sheet: drink driving in the EU and road traffic law enforcement. March 2008. http://www.etsc.be/
documents/Fact Sheet_Drink_Driving_Enforcement. pdf (accessed $\overline{13}$ Oct 2008 ).

5. Department for Transport. Statistical release: road casualties in Great Britain: 2007 estimates for accidents involving illegal alcohol levels. 7 August 2008. http:// www.dft.gov.uk/pgr/statistics/datatablespublications/ accidents/rcgb07drinkdrive (accessed 13 0ct 2008).

6. Allen P. Drinking and driving. Transport statistics. Road casualties Great Britain 2006: annual report. 2007: 26-34.
7. European Transport Safety Council. ETSC fact sheet: drink driving fact sheet. January 2008. http:// www.etsc.be/documents/Fact_Sheet_DD.pdf (accessed 13 Oct 2008).

8. Fitzpatrick J. Oral evidence to the House of Commons Transport Select Committee, Road Safety Enquiry, 16 July 2008.

9. Ladyman S. House of Commons Parliamentary Questions: speed limits: cameras. 4 June 2007.

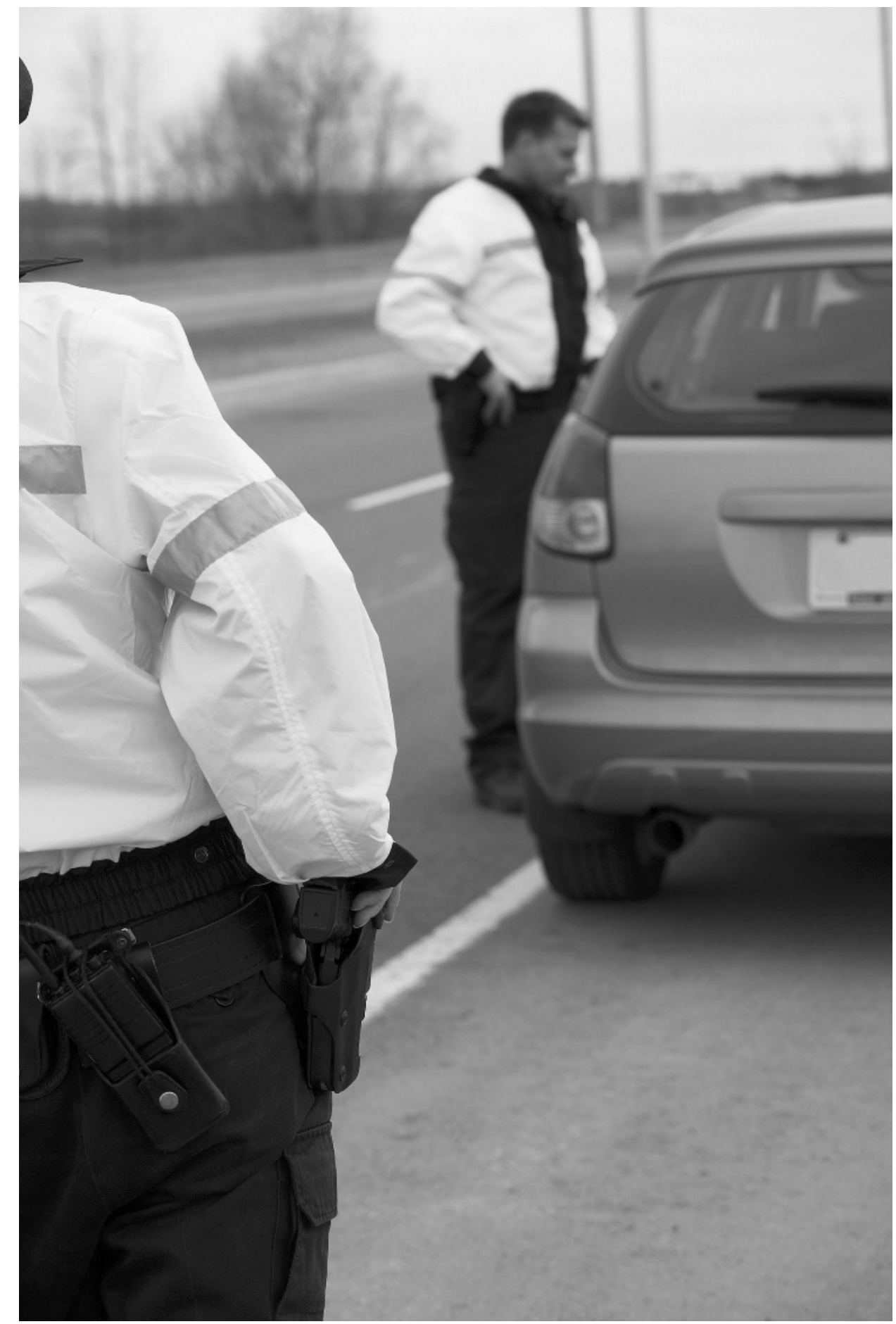

